\title{
Structuring An MBA Consulting Course: Aligning Pedagogical Strategies To Meet The Needs Of A Business School's Critical Stakeholders
}

Olivier P. Roche, Salisbury University, USA

Yvonne Downie, Salisbury University, USA

Memo Diriker, Salisbury University, USA

\begin{abstract}
At a time when business schools of second-tier universities face budget constraints, the MBA consulting program has become a vehicle to build a school's reputation and to engage the business community in order to raise financial resources. Business schools also face competition from on-line programs, and consulting assignments help to define a school's competitive advantage. Finally, an increasing number of students with little or no prior business experience are seeking the "MBA edge" to help them find their first positions. As a result, the consulting program is rapidly becoming an instrument of choice to facilitate the transition from campus to professional environment. This article presents the pedagogical strategies implemented by a university with limited resources and for which the consulting program has been designed to address the needs of both external and internal stakeholders.
\end{abstract}

Keywords: External/Internal Stakeholders; Consulting and MBA Program

\section{INTRODUCTION}

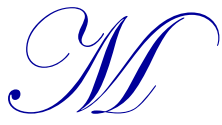

BA programs around the world are evolving rapidly. This evolution can be attributed to several factors, including the rapidly changing job market for graduates. The constant change in the marketplace means that business schools must learn to adapt and be flexible if they are to succeed.

Measuring success in the business school marketplace involves an analysis of the university's available resources as well as an assessment of how the needs of the school's stakeholders are met. Stakeholders include, among others, students, professors, administrative staff, alumni, taxpayers (if the school receives public funding), and partners in the local business community. This study focuses on small second-tier universities with limited resources, for which the support of the local business community is critical. In this particular environment, external for-profit and nonprofit stakeholders can be small, medium, or large organizations spanning many different industries. Often, for small second-tier universities located in rural areas, those industries can be family-owned businesses, agriculture, manufacturing, or tourism. Their stakeholder status means that they are highly involved, motivated, and concerned about the success of the business school in their community. Ultimately, these stakeholders are critical to the current and future prosperity of a business school.

In addition to satisfying the needs of these organizations, one must consider the prospective graduate students and what drives their selection of a graduate school. These applicants have more diverse motivations for enrolling in an MBA program as well as more diverse career and family situations than ever before. The "typical" graduate student no longer exists. The student who has just completed an undergraduate degree is only one type of prospective student. Prospective students are also individuals on mid-level career paths in corporate America, entrepreneurs, and executives who may be searching for a "convenient" way to complete their graduate degrees. All 
these different types of students are demanding consumers who have a variety of motivations for pursuing graduate degrees and have many choices of graduate business schools. Indeed, these consumers/stakeholders are responsible for the influx of options in MBA education, from on-line programs to weekend "hybrid" programs, all results of market forces. Students who are unable to find full-time careers immediately after graduating with bachelor's degrees are now opting to enroll in full-time MBA programs since entering corporate America in the current economic climate is not easy. These students have little to no experience in the corporate world and present their own challenges in a graduate classroom. Compare these students to the executive pursuing an MBA who has vast corporate experience, and one can see the complexities of the demands an MBA program must meet in order to thrive.

In this context, the MBA consulting assignment represents both challenges and opportunities. First, the students' mixed backgrounds represent a major challenge for small and medium-size universities that are not in the top tier. In the capstone class of consulting, the challenge of this mix (full-time, part-time, experienced or not, and so on) is particularly obvious. In our MBA program, consulting is the only class that is not administered in the controlled environment of the classroom - a second challenge. It is also the only class with an outcome that goes far beyond the transmission of knowledge to students - a third challenge. A fourth challenge is the inconsistency of students' motivation at second-tier schools. In highly selective programs, the quality and motivation of the students consistently are relatively high. This consistency is particularly important when dealing year after year with demanding external clients. In every consulting assignment, the school's reputation is at stake. In a less selective school, the lack of consistency represents a major risk that needs to be mitigated if the consulting program is to remain successful over a long period of time.

The MBA consulting program also presents important opportunities. First, it provides an opportunity to make experiential learning an important part of MBA education. Experiential learning has long been part of the curriculum in some of the more innovative MBA programs in the United States and elsewhere (Anonymous, 2008; Badenhausen, 2009; Fish, 2008; Li, Greenberg, and Nicholls, 2007; McHann and Frost, 2010; Prince, 2008; Rappeport, 2010; Schmidt and Richter, 2006; Sciglimpaglia and Toole, 2009; Scott, 2007). As the positive outcomes of these programs have become better known, other institutions have begun to welcome back practice into higher education in business (Harsell and O'Neill, 2010; Nokes, 2008; Raelin, 2007). These institutions report better job placement outcomes that can be linked to such experiential learning opportunities (Clark and White, 2010; D'Abate, 2010; Garcia, 2009). Finally, students report higher levels of satisfaction with programs that include experiential learning opportunities (McLaughlin, 2010; Moffit, Stull, and McKinney, 2010; Scott, 2007).

Second, a consulting class represents a great opportunity for a business school to connect with the local community and build lasting relationships with crucial stakeholders. Many business schools have a bountiful market of external stakeholders. Larger top-tier schools in highly populated areas may have easier access to corporations and funding sources, whereas smaller regional schools located in less populated areas are forced to work harder to find such stakeholders. The smaller regional business school may also have limited means and, most important, a limited number of potential client companies. This limited pool of organizations makes the regional market challenging. These few stakeholders, then, are critical to the school's reputation and success. They are alumni, future alumni, parents, future parents, influential advocates at the state and local levels for funding and other political issues affecting the university, and/or future benefactors. Creating long-lasting beneficial relationships with this limited pool becomes of paramount importance to the business school's long-term growth.

Third, in an environment where it is becoming increasingly difficult to distinguish one generic MBA program from another, the consulting class represents an opportunity to build a business school's competitive advantage and to offer to the student an experience of real value. Consulting classes in which groups of students, accompanied by a professor who is a seasoned consulting professional, work as a team on the client's premises throughout a consulting process that lasts several months to offer students an experience that cannot be easily duplicated by universities offering only on-line education.

How do we ensure that stakeholder needs are being met? How do we build ongoing support for the business school? The most direct way to serve the local business community, albeit a challenging one, is the consulting assignment, the capstone class for the MBA curriculum, which links the student consulting team (critical 
internal stakeholder), the faculty member, and the business school to the client company (critical external stakeholder). We will discuss a client-centered and market-driven approach to the MBA consulting assignment in the context of a regional business school's curriculum.

\section{CONSULTING ASSIGNMENT: AN INTEGRATED APPROACH}

At Salisbury University (SU), the consulting assignment is considered not a traditional class, but rather an interface mechanism that allows students of one organization (the business school) to meet and work with the employees or owners of another (the client). The educational benefits for the students are embedded in mutually beneficial interactions between the student/consultant teams and the client stakeholders in the local business community.

To jump start the consulting program, the business school leverages the resources available at the university level. At SU, consulting assignments are generated through various means. Within the business school, several departments and programs interact with the local business community. For instance, the Business, Economic, and Community Outreach Network (BEACON), which offers business, economic, workforce, and community development services mainly to nonprofits and very small businesses, has an extensive network of contacts in the business community.

Through programs such as BEACON, the alumni relations department, and the personal contacts of business school professors and administrators in the local business community, the consulting program's administrators establish an initial list of potential clients. As the consulting program develops, the clients from the first consulting cycle, it is hoped, will later provide support to the business school. Such support can take many forms, including donations, fees, or recommendation letters and contacts with new potential clients. In our experience, as in most business endeavors, the first cycle is the most difficult to carry off. Thereafter, depending on the success of the first assignments, subsequent cycles may be far easier to organize and implement. Figure 1 shows the cycle as well as the connections between the various stakeholders involved in the consulting project.

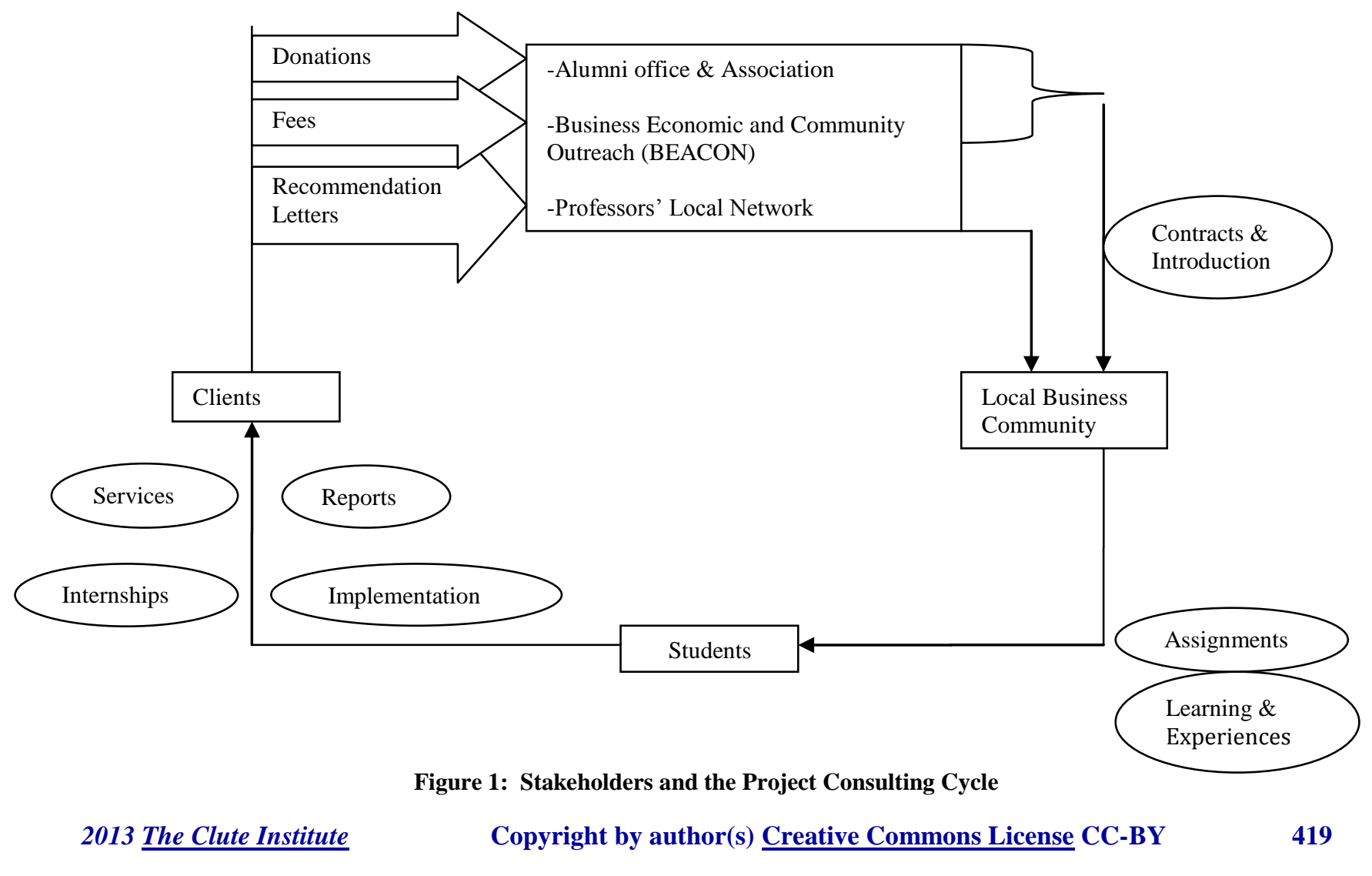




\section{CONSULTING ASSIGNMENT: A CLIENT-CENTERED APPROACH}

Although SU is a relatively small campus, its central location in a rural area and its business school's strong regional reputation make it an important, high-profile partner in the local community. The Perdue School of Business fulfills its social mandate through various means such as providing consulting services to small and medium-size enterprises. Every year, small teams of MBA students advise companies on business issues such as ways to reduce operating costs, to expand the customer base through market analysis, or to improve the use of social media marketing systems. In return, front-line managers and executives of these companies actively engage with students to find business solutions that benefit their organizations. Ultimately, through these assignments, the business school fulfills its dual mandate of helping local firms that cannot afford a private consulting firm's assistance and grooming the state of Maryland's next generation of business professionals.

Mentoring students during consulting assignments is challenging for two reasons. First, the mentor does not operate in the controlled environment of a classroom. Students have to work with clients on the clients' premises, and although the consulting services are provided for little or no charge, the standards are the same as for commercial services. Clients invest time interacting with students and they expect results at the end of the process. Second, the professor/student relationship is tested under difficult circumstances. The guiding principle underlying the consulting exercise is that there should be as little difference as possible between a consulting project at the business school and the first assignment undertaken by a graduate who has just been hired by a consulting firm. In this case, the role of the mentor is to ease the transition from campus life to the less forgiving environment of the business world. For that reason, the professional relationship of the professor with the student/consultants is likely to be tense during the assignment and even, at times, unpleasant. The clients and the professor expect a more professional outcome than is typically expected of MBA students with little or no business experience. The standard for success is high and the quality of the consulting services provided must not be compromised. In that context, the professor may sometimes be perceived as harsh and unforgiving. Students must come to appreciate that a consulting assignment is about not just learning but also delivering superior results.

\section{Concept and Guiding Principles}

Although the extant literature tends to focus on the needs of the students and the learning experience (Dallimore and Souza 2002; Leon and Tai 2004; Schmidt and Richter 2006), SU's approach is deliberately focused on achieving the client's objectives. The rationale underlying this client-centered approach is twofold. First, during a consulting assignment, students may improve their technical skills (e.g., data collection and analysis), but this improvement is not the main objective of the course. Key learning objectives are for the students to develop people skills and the professional attitude that a consultant must have in order to successfully handle the needs of a demanding client. Second, the reputation of the school is at stake and, for a consulting program to survive, clients must be satisfied. It takes years to build a program's reputation but only a few projects poorly implemented to damage it. The information rapidly spreads within the business community, reducing the school's ability to market its consulting services. Therefore, during our first meeting with the students, we emphasize that the benchmark of a successful assignment is the satisfaction of the client's needs.

Although the approach and underlying principles are the same as those used by a consulting firm operating in the private sector, a few adjustments are made to take into consideration that the assignment is actually taking place in the context of a special relationship between an academic institution and a client, and also that this is the first consulting assignment for many of these student/consultants. For instance, to facilitate the student/consultants' learning, the professor takes on the role of the consulting firm's managing partner. Throughout the assignment, the professor monitors the relationship between the students and their client, manages expectations of both parties, and anticipates problems. In this triangular relationship, students benefit from the professor's experience and understanding of the overall consulting assignment cycle (preliminary meetings, negotiation of the letter of engagement, fieldwork, report, presentation, and follow-up) while they learn to handle technical and people-related issues with their clients.

There are also subtle, but important, differences between this first experience and the one encountered during a first-year assignment at a consulting firm. Unlike a managing partner supervising several projects, the 
professor is likely to have more time (and probably more patience) to facilitate the students' learning process while meeting clients' business objectives. Very early on, students are strongly encouraged to discuss any difficulties with their professor and the professor must demonstrate that he or she is available to guide student/consultants' first steps and to help students work through the stress attached to certain situations. Students are made aware that a positive outcome is what counts, not so much the difficulties encountered and resolved during the assignment. With this endresult approach in mind, students very quickly learn to use the skills and resources available through their professors to achieve the best possible results. In that regard, the consulting class eases the transition between the student's education and his or her professional career. In the consulting class, student/consultants have to manage just the client relationship with the assistance of the professor, whereas in a real-world consulting project, consultants must simultaneously manage the client relationship and meet the profitability objectives of the consulting firm's senior management team.

\section{University and Business Community: Setting the Tone of the Relationship}

Like most business schools, the Perdue School of Business has a social responsibility to the local business community. Therefore, opinions on whether to charge fees are not always unanimous. Also, such a decision has a profound and long-term impact on the relationship between the university and the business community.

For some of our colleagues, the learning opportunity offered to the students by the client's assignment and the university's mission to provide assistance to the local community both justify the absence of fees, and others oppose charging fees because they have concerns about the ethics of the university's financially profiting from students' mandatory unpaid labor. On the other side of the debate, some of our colleagues consider consulting classes to be an opportunity for the school to raise funds at a time when other sources of financial assistance are drying up. In addition, charging fees (even nominal fees) changes the dynamics of the relationship with clients. During the negotiation of the letter of engagement, the simple mention of fees sends a signal that the student/consultants' time should not be wasted. The client should come to every meeting prepared and should supply requested information on a timely basis. Charging a fee also provides student/consultants with an additional incentive to deliver results. When money is involved, this is not only about grades.

The flip side of the coin, however, is that clients who are paying a fee for consulting services will be far more demanding with regard to the results of the assignment and far less forgiving of mistakes. This is an important consideration because in any given cohort of MBA consultants, the quality of the teams tends to be uneven, particularly in second-tier universities. Most teams deliver consultant-quality reports, but in almost every year, a team fails to deliver on its commitments to the client.

In addition to these, two other factors should be considered in deciding whether to charge fees for students' consulting services. First, one should take into consideration the characteristics of the client (for-profit versus nonprofit, large versus small organization). Obviously, the school's social responsibility is relatively more important when the client belongs to the local nonprofit sector or is a start-up. Second, one should also consider the business school's consulting track record. It may not be advisable (or even feasible) to charge clients until the business school has established its credentials. Therefore, during the first three or four years, a better (and more achievable) objective would be to obtain recommendation letters from satisfied clients. Once the school's consulting credentials have been established and recognized, the professor has the option to negotiate fees for subsequent assignments.

\section{Class Composition and Supervision}

Although SU is a relatively small campus (less than ten thousand students), the strong regional reputation of its business school and the paucity of MBA programs within a two-hour drive make it an important player in the local business community. The business school has a relatively large undergraduate student body; but with about thirty full-time graduate students, the MBA program is small. To graduate, each MBA student must complete a consulting assignment during the last two semesters of his or her degree program.

Table 1 provides additional information on the profile of the student enrolled in the MBA program as well as the evolution of these profiles over the last six years. The student body is diverse. About two-thirds of the class is 
composed of local students and mid-career professionals. In addition, the business school has exchange programs with three universities in Europe and one in China. The Technical Institute of Berlin sends three or four engineers every year. The business schools of Rennes and Grenoble in France and of Dalian in China each send one or two students per year to take a semester at SU or complete a dual degree. An increasing number of students come to the MBA program right after completing their bachelor's degrees. The motivations of these students vary. A few are completing dual degrees (engineering, accounting, etc.); others believe that it is difficult to enter a competitive job market with only a bachelor's degree, especially if their professional experience is limited. This lack of business maturity has to be taken into consideration when selecting assignments as well as deciding whether to charge fees for consulting services. Finally, the mix of part-time and full-time students is also a factor to consider for assignments which, by their nature, have workloads that fluctuate throughout the consulting period.

Table 1: MBA Population - Franklin P. Perdue School of Business, Salisbury University (2006-2011)

\begin{tabular}{|l|c|c|c|c|c|c|}
\hline & \multicolumn{7}{c|}{ Enrollment in MBA Program (Percent) } \\
\hline \multicolumn{1}{|c|}{ Year } & Fall 2006 & Fall 2007 & Fall 2008 & Fall 2009 & Fall 2010 & Fall 2011 \\
\hline Male & 48 & 44 & 48 & 56 & 63 & 70 \\
\hline Female & 52 & 56 & 52 & 44 & 38 & 30 \\
\hline Full-Time & 43 & 46 & 45 & 33 & 34 & 47 \\
\hline Part-Time & 57 & 54 & 55 & 67 & 66 & 53 \\
\hline
\end{tabular}

The consulting assignment is supervised by experienced professors who have either been consultants or have managed teams of consultants prior to or during their academic careers. For teaching most business courses, past business experience is optional but considered an advantage. For managing a consulting assignment, that the professor have past business experience is recommended for multiple reasons. First, a professor has to establish his or her reputation in the local business community. Having a discussion with a nonprofit organization asking for free advice is relatively easy, but marketing paid services to small businesses and corporations is more challenging. As for any other consultant, past experience and a track record of successful transactions are important marketing tools to establish a professor's credentials. Second, unlike most business courses, the consulting assignment is more about people skills than technical skills. For instance, assessing a client's true needs is not always straightforward. More often than not, the consultant has to clarify and redefine the scope of the assignment initially proposed by the client. Also, the word client often encompasses multiple stakeholders both within and outside the organization.

Anticipating problems before they become unmanageable is also a critical part of the job description of a professor teaching consulting. The dynamics and timetable of each project are different. Furthermore, some clients are more difficult than others and student/consultants have to deal with every organization's internal politics. With so many stakeholders involved, the professor has to make sure that the client's needs are properly addressed while the school's reputation is preserved.

Thus, for this type of class, the business school needs a manager with pedagogical skills rather than the usual tenure-track professor with extensive teaching and research skills but limited business experience.

\section{Client Prescreening and Team Selection}

As noted earlier, the university markets its services through BEACON and administrators' and professors' personal contacts, among other channels. For the students, the consulting assignment starts at the end of August and ends usually in April or May the following year, but for the professors/managing partners, this is a year-round assignment. Right after the completion of one consulting cycle, professors and administrators start visiting potential clients to inform the business community of the type of services that the university is offering.

During the first meeting with potential clients, we review past assignments undertaken by students that, we believe, might be relevant to the client's profile. We also differentiate our services from other services provided by the university. Many clients fail to understand the difference, for example, between internships offered to undergraduate students to help their transition to the job market and consulting work done by MBA students (who are often mid-career professionals). In the former, students perform certain basic tasks and are involved in the implementation phase of a given strategy. In the latter, students analyze problems and issues and propose solutions. 
They are not (and should not be) involved in the implementation phase of the proposed strategy. In a few instances, successful consulting assignments recommending marketing fieldwork can lead to the client's offering internships to undergraduate students to implement some of the recommendations.

A second point that is emphasized during preliminary meetings is that the client will have to invest a substantial amount of time in the consulting assignment. Again, this is not an internship involving a short briefing of the students on a simple task to be performed or a straightforward objective to be achieved. Reminding clients that they will have to invest time is particularly important when there are no fees involved. In that case, clients have a tendency to consider the student/consultant's time unlimited and free. After a brief summary of the project, such clients usually leave the student/consultant on their own to do the job. If the consultants "hit the mark," it's a positive outcome. If they don't, then it does not matter since the services are free. Even in the scenario where the outcome is positive, interaction with the client - and therefore the students' learning experience - is limited. Finally, during the preliminary meeting, the professor/manager can assess the resources available for the student/consultants to perform the job and the willingness of the clients to be involved in the whole process. This, in turn, offers the professor a clear indication of the time that will be needed to manage a specific assignment.

Prescreening of the projects and team selection is an iterative process. The professor has reviewed the profiles of the student/consultants before the meetings with potential clients. For instance, a team composed of midcareer professionals will be able to handle assignments with management and strategic issues, whereas a team composed of younger students with limited professional experience will be more at ease handling a project on a Web marketing portal or the use of social networks. In the past, many companies with senior marketing teams have asked our consultants to improve the way they interact with their younger customers via the Internet. Also, knowing that 20 percent of the class has an engineering background, for example, would allow the professor to accept consulting projects that are more upstream (i.e., closer to the production than to the marketing phase).

It is the professor's responsibility to organize the students into teams. A consulting assignment is not about friendship and intellectual or emotional affinity among students; it is about team performance. The formation of the team follows a five-step process:

\section{$\underline{\text { Step One }}$}

The professor/managing partner discusses students' backgrounds with the MBA director. The consulting assignment is usually undertaken during the last two semesters of the MBA program and the director has had many opportunities to meet students and assess their people and leadership skills. It is the right time to ask if there is any issue that the professor/managing partner should be made aware of - for example, family issues (such as death in the family or an ongoing divorce), professional issues (mostly related to the fact that some students are already working full-time and have less time available for the assignment), and personal issues (such as bad attitude or unprofessional behavior) - that are preferable to discuss before the students meet with clients.

\section{$\underline{\text { Step Two }}$}

Students interview their classmates. The class is divided into teams of two students who will interview each other. Two questions should be answered: (1) each student should rank the projects in terms of his or her preference and (2) each student should detail the strengths and knowledge that he or she would bring to the team for each of the projects being put forward. Each interviewer provides the professor with a written summary of the interviewee's responses.

\section{$\underline{\text { Step Three }}$}

Some projects are more quantitative than others. Also, depending on the client's profile and the scope of the project, people skills may be more relevant for a specific assignment. The background information collected during step two is usually good enough to form teams with the right set of skills. Two competing teams will work on each project. Competition is introduced at an early stage for three reasons. First, competition increases students' motivation. Second, one team usually performs better than the other and this helps when the time comes to grade 
performance. The client benefits from two different approaches to the same project. During the final presentation, the teams emphasize different approaches and often different solutions emerge. Finally, as mentioned earlier, often one team does not deliver consulting-quality performance. Having two teams working on the same project allows the professor to feel more confident that at the end of the assignment the client's objectives will be met. This is particularly important when the payment of fees is involved.

\section{$\underline{\text { Step Four }}$}

Teams meet their clients on the company's premises. This sets the tone of the assignment. This is not a school project but a business transaction. For this first meeting, both teams meet the client either together or separately. Based on the information collected during this meeting, each team will draft a definition of the scope of the consulting project and will negotiate the other clauses of its letter of engagement (e.g., resource requirements and timetable for delivery).

\section{$\underline{\text { Step Five }}$}

Each team selects a leader and communicates the leader's contact information to the client. Clients are usually busy and the job of the team leader is to centralize communication so that the same question is not asked twice. The team leader also sets up subsequent meetings after consultation with the team. It is worth noting the connection between steps one and five. Based on the information provided by the MBA director and the students, the professor/managing partner has made sure that each team includes at least one member with leadership skills. Although the ultimate selection of the team leader is the responsibility of the students, the MBA director and the professor have been able, over the years, to predict with a high degree of accuracy the outcome of this final step of the selection process. This part of the process is important to avoid a scenario in which one team has four leaders while another has no clear leadership.

The time invested up front in the selection of the team members pays valuable dividends. A team with a clearly identified leader composed of members with complementary skills tends to perform better and requires less supervision from the professor at the back end of the consulting assignment process.

\section{Course Format: Being Flexible and Responsive to Client Needs}

The extant literature does offer useful guidelines to structure a consulting assignment in an academic setting (Caldarola, 2008; Cherrington and Stocks, 1986; Culver, Pilafidis, and Sathe, 1998; Kolenko and Covin, 1994; Romney, Cherrington, and Knighton, 1993).

Lecturing is probably not the most effective way to teach consulting - a field of expertise that is better learned on the client's premises. Consulting requires both people and technical skills. The former are the most difficult to acquire and doing so is the main pedagogical objective of the assignment. During the consulting assignment, students will have the opportunity to appreciate the complexity of the client/consultant relationship as well as the special dynamics of each team and project. Thus, at SU we use a dual approach centered on the dynamics of the consulting assignment. Each client, each consulting team, and each project being different, the structure of the course has to be flexible and adaptive enough to handle the ongoing changes occurring simultaneously in several projects with unsynchronized timetables.

During the first semester of a two-semester assignment, the class is scheduled to meet one evening each week for about ninety minutes to discuss progress on each project and also to discuss business cases or hear guest speakers with special expertise relevant to consulting. The class is scheduled to meet once a week so that the professor has a time slot reserved to meet the class at a given location. With the whole class in one room, this is a great opportunity for the instructor to be regularly updated by all the teams working on various assignments in different locations. Depending on the dynamics of each project, however, the professor may decide to skip a class meeting or two, instead using that time to meet with groups separately to discuss issues that are unique to each project. 
The main objective of these regular meetings is to help the professor keep track of the progress being made. It also helps the students to remain focused on the deadlines for their respective projects. The content of class meetings is very informal and after the projects update, the class discusses business cases. The discussion of these cases broadens the students' understanding of the consulting profession and it is also an occasion to link consulting with other business courses (strategy, marketing, and business law, to name a few). These cases allow the professors to open discussion on special topics that are relevant to the consulting field but are unlikely to be discussed on the client's premises or during the assignment; for instance: (1) issues related to the start-up of a consulting firm, (2) whether a consulting firm should remain private or go public, (3) if a consulting firm decides to go public, how the consultant's remuneration package affects his or her relationship with clients, (4) what happens in a succession or when there is a disagreement between partners, and (5) what issues are involved with the merger of two consulting firms.

Caldarola (2008) discusses examples of consulting programs at two universities (Cornell and Syracuse). At Cornell, "the general design for these projects included $50 \%$ class time and 50\% work on the consulting project" and at Syracuse, there are "requirements that each of its MBA consultants spend no less than nine hours a week over a semester working on the consulting project." The rationale underlying these very specific time requirements is not clear; it may be related to the specific projects undertaken. At SU, we do not impose any specific time requirements, but we inform the students that a consulting assignment is time-consuming and that they should set aside at least five hours per week during the preliminary phase of the assignment. Beyond this basic recommendation, we inform the students that there are many variables that will affect their weekly schedule: (1) the type of project, (2) the type of client and its needs, as well as the client's availability to move forward with the project, (3) the scope of the project described in the letter of engagement, and (4) the phase of the consulting assignment (letter of engagement negotiation, fieldwork, preliminary presentation of findings, preliminary report, final report).

In other words, every project has a different timetable and dynamics. Students have to be responsive to their clients' needs and also be available when their (usually) busy clients are. During some periods, they may have to work only a couple of hours a week; but during others, they may have to be available ten to fifteen hours per week.

In addition, the assignment may not necessarily follow the academic cycle (e.g., all the information may not be available at the beginning of the semester and the final presentation may not occur during the final exam week). As a result, at $\mathrm{SU}$ we start the consulting class at the beginning of the fall semester with the understanding that the final presentation will occur sometime toward the end of the spring semester. Some projects end in February or March; others stretch to early May. Also, consulting assignments tend to be more demanding during the second half. Therefore, cases, advice, and consulting issues are discussed during the fall semester. In the spring, the student's main assignment for this class is to complete the fieldwork and write his or her report.

\section{CONCLUSION: A MARKET-DRIVEN APPROACH TO THE CONSULTING AGREEMENT}

\section{Lessons Learned from the Trenches}

For many students, the consulting assignment represents their first interaction with the business world, while for professors it represents a challenging endeavor outside the controlled environment of a classroom. Therefore, even at the risk of appearing trivial, a few points need to be stressed. Student/consultants (particularly the younger ones) present three characteristics that have been responsible for most of the problems in the professor/student/client relationships. First, students do not know how to manage their time. Their mentality is to cram for the consulting assignment the way they cram for exams. This simply does not work, but they tend to understand that only toward the end of the assignment, when it is too late. Therefore, there is a need to constantly monitor their progress and send unequivocal signals when deadlines are not met. Second, students tend to treat their clients the way they treat their parents and professors. The culture of entitlement is pervasive among students and does not go over very well with clients. A consultant needs to be respectful when asking questions, but some students convey the attitude that they know their client's business better than the client does. Third, students need to be aware that their client will not be available whenever they need him or her. More fundamentally, students need to be reminded that the primary purpose of the assignment is to provide services to a client and only secondarily for the 
student to learn from the process, not the other way around. Finally, a few students care more about their grades in the course than about the outcome of the assignment. This is unfortunate and, to address this issue, students must be made aware at the beginning of the assignment that the client's evaluation constitutes 50 percent of their final grade.

\section{Closing the Loop}

This review of pedagogical strategies for the MBA consulting assignment started with the analysis of the university's resources to find contacts and assignments. Consulting is essentially a market-driven activity. The success of the program lies in the business school's ability to find a reliable flow of assignments that are consistently executed to the satisfaction of the clients over a long period of time. For the first cycle, finding assignments when the reputation of the school has not yet been established can be difficult. Therefore, it is essential to follow up on successful final presentations with a request for contacts and recommendation letters to help promote the next consulting cycle.

Recommendation letters are not only used to promote the services of the business school; they also serve as recommendation letters for students with limited professional experience. Clients are usually asked to list in their letter the names of the consulting team members as well as the length of the assignment. A positive evaluation by a senior executive for a project that lasted several months speaks volumes about a student's professional behavior and ability to meet deadlines. For the best students, the instructor who supervised the assignment can also provide letters of recommendation to support their applications for specific jobs.

Finally, successful consulting assignments have the potential to generate financial resources for the business school. For second-tier universities with a limited consulting track record, charging fees for the assignment may not be an option. Highly successful consulting projects can, however, set the stage for follow-up calls by the dean and the alumni and development offices seeking support for the business school's activities in the long term.

In addition to generating financial resources for the institution, the MBA consulting assignment increases the marketability of the MBA graduate - an important consideration for students applying to a specific graduate program. The MBA degree used to be open only to professionals with managerial experience and it was perceived as a necessary credential for making a career transition to more senior levels. This may still be the case for degrees from top-tier universities. The second-tier programs, however, are more frequently enrolling students with limited professional experience. Therefore, the increasing relevance of the consulting course is a reflection of changing market needs of both students and employers. In this new environment, the consulting assignment deserves more than a cursory consideration in the design of a modern MBA curriculum.

\section{AUTHOR INFORMATION}

Dr. Olivier Roche is an Assistant Professor of Management and International Business at Salisbury University. Dr. Roche is the author of Corporate Governance and Organization Life Cycle (Cambria Press, 2009). Professor Roche holds degrees from the law school of Georgetown University (L.L.M.) and from McGill University (Ph.D.). He is a licensed attorney in the State of New York. Prior to his academic career, he worked at the World Bank in Washington, DC, and as an investment banker in Hong Kong and Tokyo. In these positions, he supervised consultants and was himself lead consultant for the Bank of Tokyo-Mitsubishi. E-mail: oproche@salisbury.edu (corresponding author)

Ms. Yvonne Downie is the MBA Director at Salisbury University, where she received her master's degree in business administration. Before returning to academia, Yvonne spent more than a decade in the telecommunications/manufacturing industry. Her project management experience includes extensive consulting with global commercial, military, and government projects in several countries. Her teaching experience includes classes in global information systems management and foreign languages.

Dr. Memo Diriker is the founding Director of the Business, Economic, and Community Outreach Network (BEACON) of the Franklin P. Perdue School of Business at Salisbury University. Dr. Diriker obtained his MBA and DBA from Memphis State University. Dr. Diriker has advised private-, public-, and nonprofit-sector organizations. 
His current and former clients include U.S. Steel, Allied-Signal, Dow Chemical, Mass Mutual, Federal Express, Perdue Farms, and Peninsula Regional Medical Center.

\section{REFERENCES}

1. Anonymous. 2008. Pepperdine University surpasses 100th "live case" MBA consulting project. Business and Finance Week, February 11, 220.

2. $\quad$ Badenhausen, Kurt. 2009. MBAs in the real world. Forbes, August 24.

3. Caldarola R. 2008. Client-based consulting: A case study in the MBA program. Proceedings of the European Applied Business Research (EABR) and College Teaching and Learning (TLC) Conferences, Rothenburg, Germany.

4. Cherrington, J. O., and K. D. Stocks. 1986. Educating a management consultant. Journal of Information Systems 1: 145-53.

5. Clark, James, and Gayle Webb White. 2010. Experiential learning: A definitive edge in the job market. American Journal of Business Education 3 (2): 115-18.

6. Culver, Robert, Emile Pilafidis, and Vijay Sathe. 1998. Fusing theory and practice: Honors consulting projects for Drucker MBA students. Journal of Education for Business 73 (5): 298-301.

7. D'Abate, C. 2010. Developmental interactions for business students: Do they make a difference? Journal of Leadership and Organizational Studies 17 (2): 143-55.

8. Dallimore, E., and T. Souza. 2002. Consulting course design: Theoretical frameworks and pedagogical strategies. Business Communication Quarterly 65 (4): 86-113.

9. Fish, Lynn A. 2008. Graduate student project: Employer operations management analysis. Journal of Education for Business 84 (1): 18-30.

10. Garcia, Eric-Jean. 2009. Raising leadership criticality in MBAs. Higher Education 58: 113-30.

11. Harsell, Dana M., and Patrick B. O'Neill. 2010. Experiential learning: Lessons learned from the UND business and government symposium. American Journal of Business Education 3 (8): 27-33.Kolenko, Thomas A., and Teresa Joyce Covin. 1994. Academic consulting teams: A case example and team management guidelines. Journal of Education for Business 70 (1): 38-41.

12. Leon, L. A., and L. S. Tai. 2004. Implementing cooperative learning in a team-teaching environment. Journal of Education for Business 79 (5): 287-393.

13. Li, T., B. A. Greenberg, and J. A. F. Nicholls. 2007. Teaching experiential learning: Adoption of an innovative course in an MBA marketing curriculum. Journal of Marketing Education 29 (1): 25-33.

14. McHann, James C., and Laura A. Frost. 2010. Integrating experiential learning into business courses: Using learning journals to create living case studies. American Journal of Business Education 3 (8): 1-12.

15. McLaughlin, Erin. 2010. The real world experience: Students' perspectives on service-learning projects. American Journal of Business Education 3 (7): 109.

16. Moffit, Timothy, Charles Stull, and Hannah McKinney. 2010. Learning through equity trading simulation. American Journal of Business Education 3 (2): 65-73.

17. Nokes, Timothy. 2008. Mechanisms of knowledge transfer. Thinking and Reasoning 15 (1): 1-36.

18. Prince, C. J. 2008. MBA makeover. Chief Executive October 8, 52.

19. Raelin, Joseph A. 2007. The return of practice to higher education: Resolution of a paradox. Journal of General Education 56 (1): 57-77.

20. Rappeport, Alan. 2010. MBA "games" lead to real-world investing success. CFO.com-News and Insight for Financial Executives, January 17. www.cfo.com/article.cfm/10551357?f=search , accessed September 21, 2010.

21. Romney, M. B., J. O. Cherrington, and A. Knighton. 1993. Implementing a graduate management consulting course. Journal of Information Systems 7 (1): 48-61.

22. Schmidt, Sascha L., and Ansgar Richter. 2006. Course formats for teaching management consulting. Education for Business 82 (1): 56-62.

23. Sciglimpaglia, Donald, and Howard Toole. 2009. Use of student field-based consulting in business education: A comparison of American and Australian business schools. Journal of Education for Business 85 (2): $68-77$. 
24. Scott, Mike. 2007. "Hands-on" classes draw students to MBA programs. Crain's Detroit Business, June 4, www.crainsdetroit.com/article/20070604/SUB/706010311/-hands-on-classes-draw-students-to-mbaprograms, accessed September 14, 2010. 